\title{
ESPANHÓIS NO SUL DO BRASIL: DIVERSIDADE E IDENTIDADE ${ }^{1}$
}

\author{
Spanish immigrants in the South of Brazil: \\ diversity and identity
}

Regina Weber*

\begin{abstract}
RESUMO
No estudo das manifestações de identidade étnica dos espanhóis na Região Sul do Brasil, é preciso considerar tanto o contexto das sociedades receptoras quanto o perfil dos contingentes imigrantes. Desde a segunda metade do século XIX, os estados do sul do país passaram a receber expressivos contingentes de imigrantes - entre os quais os espanhóis não são os mais numerosos - que, agregados às populações já existentes, configuraram uma sociedade multiétnica. Particularmente para o Estado do Rio Grande do Sul, os estudos apontam uma diferenciação social no perfil dos imigrantes espanhóis ao longo do século XX, o que se reflete nas formulações identitárias e no tipo de lideranças que gestionam as práticas de agregamento e propõem representações. As associações que se organizaram neste Estado fronteiriço também sofreram a influência de entidades similares existentes nos países platinos vizinhos. Analisar as manifestações étnicas dos espanhóis e seus descendentes, observando os fatores econômicos e culturais internos e externos ao grupo, é a proposta deste artigo.
\end{abstract}

Palavras-chave: imigrantes; espanhóis; identidade étnica; lideranças; trabalhadores.

\footnotetext{
ABSTRACT

In order to study of ethnic identity manifestations within the Spanish community in southern Brazil it is necessary to consider both the con-

Departamento de História e Programa de Pós-Graduação em História. Universidade Federal

1 Uma primeira versão deste texto foi apresentada como uma comunicação no II Congresso Ciencias, Tecnologías y Culturas. Diálogo entre las disciplinas del conocimiento. Mirando al futuro de América Latina y el Caribe, realizado na Universidade de Santiago de Chile em 2010.
} do Rio Grande do Sul. 
text of the receiving societies and the profile of the immigrants. Since the second half of the nineteenth century, the southern states of the country started to receive significant numbers of immigrants - among which the Spanish were not the most numerous; along with the existing populations, these foreigners shaped a multiethnic society. Particularly for the state of Rio Grande do Sul, studies indicate a social gap in the profile of Spanish immigrants throughout the twentieth century, which is reflected in the formulation of identities and in the type of leaderships which manage aggregation and propose representations. The associations organized in the border state of Rio Grande do Sul also suffered the influence of similar entities in the neighboring countries. Analyzing the ethnic manifestations of Spanish immigrants and their descendants, as well as observing the economic and cultural factors - internal and external to the group -, is the purpose of this article.

Keywords: immigrants; Spanish; ethnic identity; leaderships; workers.

A presença de espanhóis no sul do país remonta aos primórdios do povoamento, havendo mesmo autores que argumentam que os espanhóis têm um papel tão importante quanto os portugueses na ocupação da região, zona de limites indefinidos entre a América portuguesa e a América espanhola até o início do século XIX. A definição mais clara de uma condição de "estrangeiro" depende da afirmação do país como uma nação. A permissão para o acesso dos estrangeiros à propriedade da terra ocorreu um pouco antes da independência, com a presença da família real no Brasil, em 1808, justamente visando atrair europeus (SEYFERTH, 1990, p. 9). No período imperial, em meados do século XIX, a colonização passa para a responsabilidade dos governos provinciais, o que também abre oportunidade para a iniciativa privada, isto é, existiam as colônias oficiais e as colônias fundadas por companhias de colonização, contexto que favoreceu a imigração alemã para o Sul do país. As grandes levas migratórias, contudo, só vão ocorrer às vésperas da proclamação da República, quando grandes contingentes de italianos, portugueses e espanhóis entram no país, principalmente no Estado de São Paulo (SEYFERTH, 1990, p. 10). Não apenas a abolição da escravidão e a instalação do regime republicano no Brasil incentivaram a imigração, mas melhores meios de transporte e comunicação fomentaram grandes fluxos migratórios para a América. Trata-se de uma imigração de trabalhadores que, no Brasil, precisaram ser atraídos com subsídios, para fazer face à concorrência dos mercados de trabalho da Argentina e da América do Norte, com melhores escalas salariais (KLEIN, 2000, p. 23-25). 
A despeito de seu papel de antigos habitantes do território, já no censo de 1920 os espanhóis aparecem ocupando apenas a oitava posição dentre os estrangeiros presentes no Rio Grande do Sul, classificação que manterão nas décadas seguintes, apresentando menores contingentes que outros grupos (italianos, alemães, poloneses, russos, portugueses, uruguaios, argentinos). No Paraná, a presença de estrangeiros originários da Espanha é pequena em 1920 (1.817 indivíduos), mas ela foi aumentando, tanto em números absolutos quanto na sua participação porcentual entre os estrangeiros nos recenseamentos seguintes. ${ }^{2}$ Estes dados parecem apontar que a imigração espanhola para o Sul do país não teve o mesmo vigor que apresentou em outros estados do país na mesma época, particularmente São Paulo e Rio de Janeiro, sendo também ofuscada pela presença de outros grupos de imigrantes europeus. Contudo, precisamos olhar com cautela os dados oficiais, que, de resto, não avaliam a persistência de vinculações étnicas entre os descendentes. A reemigração de São Paulo para outros estados era também uma constante. O marceneiro que chegou a São Paulo em 1954 (ver abaixo) dois anos depois se dirigiu ao Rio Grande do Sul por conselho de um médico como modo de atenuar o abatimento de sua esposa, atribuído a saudades da terra natal. As palavras do médico, ele próprio filho de imigrantes italianos, "O sul é mais parecido com a sua terra", nortearam a decisão do casal (PROCHNOW, 2009, p. 84).

Entretanto, a visibilidade de um grupo étnico não é dada apenas por sua expressão numérica, mas por sua capacidade de dar-se a ver, de publicizar comportamentos étnicos (GANS, 1996, p. 431), de manifestar a identidade étnica na "ação social" (FENTON, 2003, p. 17) ou de forjar uma esfera pública visível e autônoma (NÚÑEZ SEIXAS; FARIAS, 2009, p. 114). Os modos socialmente reconhecidos de visibilização são parcialmente determinados pelo contexto e, no caso do Rio Grande do Sul de meados do século XX, noticiar comemorações e festividades nos periódicos de circulação regional era um procedimento comum a várias entidades étnicas, entre estas a Sociedade Espanhola, que, após a inauguração do seu "prédio social" em 1929, poderá, a exemplo de outras associações de grupos imigrantes,

2 Entre os estrangeiros, os espanhóis no Paraná são o 7. ${ }^{\circ}$ grupo em 1940 (3.708 indivíduos), 6. ${ }^{\circ}$ em 1950 (6.683 indivíduos), $4 .^{\circ}$ em 1960 (7.653 indivíduos). Os estudos, contudo, são bastante escassos. Kreling (1979, p. 24) faz uma breve referência ao Centro Espanhol do Paraná de Beneficência e Cultura, em Curitiba. 
demonstrar seu apreço à terra de acolhida ao festejar datas nacionais em anos marcados por fortes ideologias nacionalistas no Brasil (WEBER, 2008). A ação social também varia conforme a base social que a mobiliza. E os dados indicam uma diferenciação social entre os espanhóis no Rio Grande do Sul ao longo das décadas, que tanto pode ser devida a uma mobilidade social dos imigrantes quanto a variações no perfil dos contingentes imigrantes nas diferentes levas.

Ainda não foram realizados estudos específicos sobre as primeiras entidades mutualistas espanholas do Rio Grande do Sul, criadas em cidades de fronteira do Brasil com o Uruguai e Argentina (Bagé, em 1868; Uruguaiana, em 1876; Livramento, em 1879), mas as informações existentes sugerem menos uma configuração predominantemente operária ou artesanal de sua base associativa e mais camadas, que, após algumas décadas, estavam inseridas em redes locais detentoras de poderes sociais e políticos. Para citar um exemplo, os espanhóis de Uruguaiana, entre os quais muitos "instalaram, por conta própria, suas oficinas, adquiriram campos, criaram gado ou se dedicaram a profissões liberais", pouco teriam recorrido aos auxílios da mutual; e sua condição de pioneiros foi objetivada na bandeira do município, que ostenta as cores da bandeira espanhola (VARGAS, 1979, p. 375,378$).{ }^{3}$ Como é comentado adiante, havia também na cidade operários espanhóis que atuaram em uma identidade sindical de Uruguaiana sem recorte étnico. A Sociedad Española de Beneficencia y Socorros de Bagé recebeu diplomas de Benemérita, por auxílios na área da saúde, ainda no século XIX e, na década de 1930, construiu um Panteon no centro do cemitério local, descrito pela pesquisadora, talvez com certo exagero, como "sem igual na Arquitetura do Rio Grande do Sul":

Em mármore branco, tem uma necrópole coletiva de uso social. Seu formato é quadrangular na base, indo terminar em forma de torre. No alto, o Escudo Espanhol, e, em suas laterais, insígnias das conquistas da Espanha e suas armas. No seu corpo, possui nichos. O Panteon, para eles, representa a união eterna dos espanhóis, mesmo depois da morte (KRELING, 1979, p. 32).

3 As dissertações de Wilma Ferreira Kreling e Iolanda Guimarães Vargas, recorrentemente citadas, são parcialmente utilizadas neste texto como fontes primárias, pois as centenas de páginas das duas obras contêm, além de interpretações das autoras, transcrições de documentos que hoje não estão mais acessíveis aos pesquisadores e relatos de depoimentos obtidos há mais de trinta anos, igualmente preciosos. 
Alguns jazigos familiares de Bagé foram esculpidos pelo imigrante espanhol André Arjonas e seu filho Mário (CHARÃO, 2009) ${ }^{4}$ o os imóveis que serviram de sede para a sociedade espanhola foram utilizados também por entidades de cunho elitista, como o Clube Comercial e o Aeroclube de Bagé (KRELING, 1979, p. 30-31). Em Livramento, em 1905, poucas décadas após a fundação da entidade mutualista, já era construído um Pantheon no cemitério local (VARGAS, 1979, p. 379).

As associações de espanhóis existentes em Uruguaiana, Livramento e Bagé, que são cidades de fronteira ou, no caso da última, localizada próxima à divisa internacional, demonstram a influência da organização mutualista do Uruguai e da Argentina sobre estas entidades gaúchas ${ }^{5}$, decorrente, em grande parte, do trânsito de imigrantes pela fronteira sul. Os imigrantes espanhóis do Uruguai foram os pioneiros na criação da Associação Espanhola de Socorros Mútuos em 1853, cujo modelo se expandiu para o resto da América do Sul (ZUBILLAGA, 2000, p. 149). Mais que influência, havia ação conjunta. A entidade da cidade de Livramento era a Sociedad Española de Socorros Mutuos de Santana y Rivera, isto é, uma associação binacional que oferecia socorros a sócios das cidades geminadas de Rivera, no Uruguai, e Santana do Livramento, no Brasil (SILVA JR., 2004, p. 133). Esta experiência de populações que possuem "cultura imigratória" (SOUTELO VÁSQUEZ, 1998, p. 110) também se manifesta nesta estratégia de memória que constitui o "Phanteon Espanhol", destinado a guardar os restos mortais dos sócios mais antigos. Em Porto Alegre, os imigrantes espanhóis construíram um cemitério próprio a partir de 1906, mas não realizaram o projeto do panteon por dificuldades econômicas (VARGAS, 1979, p. 111-112). A valorização dos túmulos dos "fundadores" como um lugar de memória para o grupo, simbolizando os laços existentes entre os descendentes, é encontrada também em outros imigrantes (WOORTMANN, 2000, p. 216).

Segundo Beatriz Loner (1999, p. 114, 398), na cidade portuária de Rio Grande, também próxima à fronteira, lugar de expressivo movimento operário, existiu uma sociedade beneficente desde 1895 até pelo menos 1920,

4 André Arjonas era filho do arquiteto espanhol Carlos Frias Arjonas, que emigrou com a família no final do século XIX (BELLOMO, 2008, p. 33).

5 No Brasil, o termo "gaúcho" refere-se aos habitantes do Estado do Rio Grande do Sul. 
e, entre 1928 e 1932, havia o Centro Espanhol de Socorros Mútuos, o qual, no período da guerra civil espanhola, deu origem ao Centro Republicano Espanhol e de Amigos da Espanha, onde antigas lideranças operárias se faziam presentes. Com base em alguns dados esparsos sobre a organização operária nas cidades vizinhas de Rio Grande e Pelotas, a autora destaca a influência do movimento operário da Argentina e do Uruguai sobre o brasileiro (LONER, 1999, p. 289). Também em Alegrete era significativa a presença de imigrantes e descendentes de espanhóis no movimento operário dos anos 1915-1929 (CORRÊA, 2010, p. 188).

Uma categoria que reuniu imigrantes espanhóis na inequívoca condição de operários foi a dos mineiros. Os dados existentes apontam para levas de trabalhadores que ingressaram desde a primeira década do século XX. Nas décadas seguintes, eles já haviam se organizado em sociedades, pois existiu uma entidade espanhola de socorros mútuos na cidade de Triunfo (VARGAS, 1979, p. 394), e, em relatório de 1936, a Socorros Mútuos de Porto Alegre relacionava 74 sócios "extrarradios" residentes na região carbonífera, isto é, fora do âmbito de ação da entidade da capital (SILVA JR., 2004, p. 134). Entre os registros que dispomos destes imigrantes estão processos de pedidos de indenização por acidente de trabalho nas minas (KLOVAN, 2009, p. 32-34). Uma das principais avenidas de Arroio dos Ratos, outra cidade da região carbonífera, denomina-se "Espanha".

Se as cidades da fronteira apresentam uma população imigrante que, em pouco tempo, passa a compor uma espécie de elite local, e se, por outro lado, em algumas cidades com concentração operária os espanhóis estão presentes nas organizações de trabalhadores, em cidades cosmopolitas como a capital do Estado vamos encontrá-los em posições bastante diversificadas. Entre os quarenta e sete signatários do documento que funda a Sociedade Espanhola de Socorros Mútuos de Porto Alegre, em 1893, quase metade deles podem ser identificados como artesãos: seis carpinteiros, quatro sapateiros, três alfaiates, dois marceneiros, dois artistas, dois tipógrafos, além de um padeiro, um ferreiro, um barbeiro e um pintor. Havia ainda dez ocupados com "comércio" e cinco com "indústria", sem que possamos ter clara qual a atividade designada pelo termo. ${ }^{6}$ Nos anos seguintes, os registros apontam uma maioria cuja profissão é "comércio", seguida por "jornaleiro"

6 Registro General de Socios Desde La Fundación apud Vargas (1979, p. 122-124). 
(equivalente a "diarista") e "sapateiro", e há vários associados registrados como "banqueiro", certamente tratando-se de funcionários de bancos. ${ }^{7}$

Atividades que concentraram imigrantes espanhóis entre os trabalhadores da capital foram aquelas ligadas à construção. ${ }^{8}$ As obras de pavimentação e alargamento das ruas de Porto Alegre, iniciadas em 1913, trouxeram à cidade muitos trabalhadores de outras regiões do país, mas também de outros países, particularmente de Portugal e Espanha (BILHÃO, 2005, p. 130). Em abril de 1916, é fundado o Sindicato dos Canteiros, Calceteiros e Classes Anexas, que, em março de 1917, desencadeou uma greve contra a empresa de calçamento, durante a qual ficaram visíveis tanto a proeminência dos trabalhadores espanhóis na categoria quanto a existência de tensões entre estes e os trabalhadores nacionais. Ao longo do movimento, ocorreram conflitos que resultaram em três operários feridos e num morto e o processo judicial daí decorrente permitiu à historiadora Isabel Bilhão realizar algumas interpretações: os espanhóis eram um grupo, comparativamente, bastante alfabetizado; estavam mais qualificados que os trabalhadores nacionais para o trabalho nas pedreiras e no calçamento, $o$ que lhes conferia poderes de negociações com os empresários e papéis de liderança no movimento grevista; contavam com um mercado de trabalho favorável, que incluía as capitais platinas e que lhes possibilitava mobilidade. Um mercado de trabalho internacionalizado estava em paralelo com uma organização operária articulada transnacionalmente, como se pode deduzir da correspondência do sindicato porto-alegrense com a Federación Sudamericana de Picapedreros de Montevideo (SILVA JR., 2004, p. 451).

Do ponto de vista das autoridades, informadas pelos depoimentos sobre o porte de armas, ameaças e agressões, os grevistas espanhóis foram associados às "tendências assassinas dos anarquistas espanhóis" (apud BILHÃO, 2005, p. 141). É certo que Sindicato dos Canteiros em Porto Alegre era controlado por lideranças anarquistas (SILVA JR., 2004, p. 450); contudo, o tom categórico das afirmações acusadoras não pode ser dissociado do que ocorria em outros lugares do país, como no Rio de

7 SOCIEDAD ESPAÑOLA DE SOCORROS MUTUOS DE PORTO ALEGRE "Registro general de los socios fundadores y de todos los proymentes...".

8 A presença de imigrantes espanhóis, particularmente galegos, no setor da construção é expressiva também nos Estados de São Paulo (PERES, 2003) e Rio de Janeiro (SILVA, 2006). Sobre a imigração da Galícia espanhola para o Rio Grande do Sul, ver Weber (2010). 
Janeiro, onde encontraremos elementos semelhantes: maior qualificação dos trabalhadores estrangeiros, que se refletia no seu grau de organização; vinculação dos imigrantes espanhóis ao anarcossindicalismo; participação em greves e movimentos; reação das elites no sentido de contrapor os estrangeiros aos trabalhadores nacionais, enquadrando os primeiros como "perigosos" (SILVA, 2006, p. 409-434).

Além de trabalhadores braçais qualificados, artesãos e profissionais com conhecimentos técnicos especializados ${ }^{9}$, havia em Porto Alegre imigrantes que prescindiam de qualquer organização operária ou mutualista para garantir boas condições de sobrevivência na nova terra. A Sociedade de Socorros Mútuos criou a categoria de "sócios protetores", definida pelo estatuto de 1909 como aqueles que "renunciassem espontaneamente a todos os auxílios da Associação, exceto ao lugar póstumo" (VARGAS, 1979, p. 128). A Policlínica que funcionou entre 1936 e 1950 era dirigida e contava com serviços médicos de alguns imigrantes espanhóis que compõem, com engenheiros, advogados, industriais, artistas e intelectuais, a listagem de espanhóis "ilustres" elaborada por Vargas (1979, p. 154-191). A entidade, por outro lado, poderia congregar patrões e empregados e atuar como mediadora entre ambos:

Neste propósito, era[m] oferecido[s] do recém-chegado nome, domicílio, idade e profissão, arte ou ofício, que, colocados em "quadro de avisos", permitiam que os sócios donos de estabelecimentos comerciais e industriais, professores de arte e ofícios, e ainda, particulares, pudessem cooperar com o benefício mútuo, dando ocupação aos que necessitassem quando julgassem necessário o concurso de seus serviços (VARGAS, 1979, p. 209).

Vários desses notáveis foram os que norteavam os rumos da comunidade espanhola porto-alegrense, ocupando ou não cargos na direção da associação, operando com um suporte de liderança que Zubillaga (2000, p. 152-155), analisando a imigração espanhola no Uruguai, denominou "prestígio econômico", quando se trata daqueles que alçaram a condição de proprietários e estavam em condições de abrir postos de trabalho aos

9 Comentários sobre vários desses profissionais estão em Weber (2010). 
recém-chegados, e "prestígio profissional", no caso de médicos e advogados, que podiam atuar no mutualismo assistencial ou na representação em situações de litígio. Para a geração de imigrantes do final do século XIX, o hispano-brasileiro Ignácio Montanha, o fundador, em 1890, da Escola Brasileira, educandário "frequentado pelos meninos das mais ilustres famílias da capital e do interior" (HOMENAGEM, 1928), era um referencial importante. Montanha consta como sócio benemérito da Socorros Mútuos já na segunda década do século XX, particularmente por suas preocupações com o ensino de espanhol aos filhos dos imigrantes (VARGAS, 1979, p. 253). Muitos de seus alunos tornaram-se jornalistas, deputados e governadores, inclusive o futuro presidente Getúlio Vargas. Montanha também se destacou, para além de seu grupo, por ensinar gratuitamente a pessoas sem recursos (SCHMIDT, 2002, p. 41).

O mais destacado dos imigrantes espanhóis foi o arquiteto Fernando Corona, que tem um lugar de projeção na arquitetura do Sul do país. Além de escultor e arquiteto, Corona foi escritor e orador influente. Na década de 1920, realizou gratuitamente o projeto para a sede social da Sociedade de Socorros Mútuos de Porto Alegre e esculpiu ele mesmo a bela fachada do edifício (VARGAS, 1979, p. 81, 93). Era reconhecido pelos emigrados e falava em nome dos espanhóis rio-grandenses. Nas comemorações do centenário da Revolução Farroupilha, em $1935^{10}$, quando a comunidade espanhola entrega à cidade de Porto Alegre a Fonte de Talavera, belíssimo monumento instalado em frente ao Paço Municipal, Corona foi o orador que fez o "discurso de agradecimento, em nome da colônia espanhola, ao povo gaúcho" e também realizou as restaurações que se fizeram necessárias posteriormente (VARGAS, 1979, p. 279-289). Na década de 1970, quando os espanhóis porto-alegrenses ainda se encontravam divididos em função dos acontecimentos dos anos trinta (ver abaixo), Corona fez o projeto da Casa de Espanha, entidade que agregou dissidentes da Sociedade de Socorros Mútuos desde a década de 1950 (KRELING, 1979, p. 180). O republicanismo antimonarquista que causou a fuga de seu pai da Espanha

10 O movimento separatista do Rio Grande do Sul, que perdurou de 1835 a 1845 , foi denominado Guerra dos Farrapos, em uma referência às condições dos resistentes. É o evento histórico mais importante do Estado e foi consagrado historicamente como uma "revolução". Nas comemorações de 1935, outros grupos imigrantes realizaram homenagens aos gaúchos. 
DETALHE DA FACHADA DO PRÉDIO QUE FOI SEDE DA SOCIEDADE ESPANHOLA DE SOCORROS MÚTUOS DE PORTO ALEGRE. O PROJETO ARQUITETÔNICO E AS ESCULTURAS SÃO DE AUTORIA DE FERNANDO CORONA. FOTO DE 2010, ACERVO DA AUTORA.

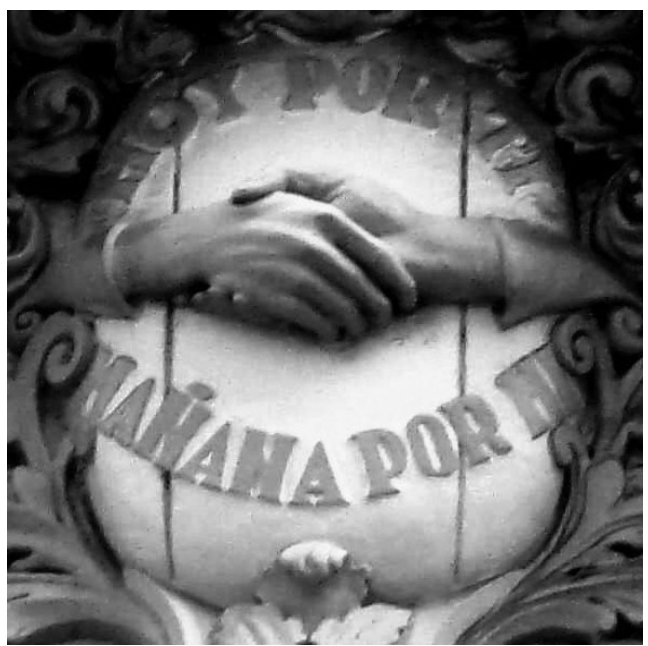

para Buenos Aires em $1909^{11}$, somado à sua posição na nova sociedade, pode tê-lo mantido equidistante tanto dos nacionalistas quanto dos radicais emigrados da década de cinquenta.

Tanto Montanha quanto Corona têm aquelas características de um "carisma" de liderança que não está isento de fatores históricos, entre os quais a aprovação da sociedade majoritária (NÚÑEZ SEIXAS, 2006, p. 26). O reconhecimento entre seus conterrâneos lastreava a receptividade do líder entre os outros habitantes da cidade; por sua vez, esta notabilidade era apropriada pela comunidade para atribuir-se uma imagem positivada. Como contraponto, vejamos o caso do escultor André Arjonas, que pouco consta

11 Jesus Maria Corona foi também um arquiteto muito reconhecido na época. Ele foi contatado na Argentina por João Vicente Friederich, proprietário de uma oficina de escultura em Porto Alegre, e reemigrou para o Brasil, estabelecendo em 1914 uma oficina em sociedade com um imigrante milanês, onde Fernando Corona passou a trabalhar. Por litígios com a Cúria Metropolitana a respeito do projeto para construção da catedral, Jesus Corona transferiu-se para Pelotas e depois, em 1922, retornou à Espanha (CANEZ, 1998, p. 31-36). 
nos registros históricos associados às manifestações dos espanhóis. Foi dele o primeiro projeto do "edifício social" da Sociedade de Socorros Mútuos, divulgado em 1918 (VARGAS, 1979, p. 77), mas o projeto que acabou sendo implementado é de autoria de Corona. Sua posição de anarquista ligado à Escola Eliseu Reclus (SCHMIDT, 2002, p. 167), que utilizou seus talentos artísticos em defesa das causas pelas quais lutava, não habilitava Arjonas a ser um mediador de populações emigradas no contexto conservador do início do século XX:

Além de suas atividades como escultor, teve atuante ação nos meios operários e carnavalescos, tendo sido o fundador de uma aula de desenho para operários; cenógrafo e diretor artístico da sociedade carnavalesca "Tenentes do Diabo", da qual foi um dos fundadores, onde aproveitava a ocasião para denunciar a exploração do povo. Seus carros alegóricos, "Aguenta Bestas", onde denunciava os altos impostos pagos pelo povo, e "Carestia”, crítica da elevação dos preços, fizeram furor (BELLOMO, 2008, p. 34).

Quando Silva Jr. (2004, p. 206) afirma que a Sociedade Espanhola desviou-se do padrão "dirigentes de alto status e associados de baixo" das entidades mutualistas da capital por manter "trabalhadores manuais" em cargos de direção, provavelmente está incluindo nesta categoria artesãos e donos de oficinas. Como é conhecido, nas associações mutualistas há uma sobrerrepresentação de profissões não manuais ou manuais qualificadas que não oferecem uma imagem do grupo em seu conjunto, dando uma imagem elitista deste (NÚÑEZ SEIXAS, 2006, p. 24). ${ }^{12}$ Esta discussão nos remete ao debate sobre identidade de classe e identidade étnica, sendo esta última não raro vista como prejudicial à primeira e passageira (LONER, 1999, p. 116). A visão de que tendências seculares de aculturação e assimilação culminariam na eventual absorção do grupo étnico em uma mais ampla cultura, denominada por Gans (1996, p. 426) de "teoria em linha reta", era a abordagem sociologicamente dominante de etnicidade até décadas atrás.

12 Segundo Loner, as sociedades beneficentes étnicas ou de nacionalidades formavam o grupo mais importante entre as sociedades mutualistas existentes na região de Pelotas e o comando destas associações "costumava ficar com os membros da comunidade melhor sucedidos economicamente, com maior poder de influência e prestígio" (LONER, 1999, p. 116). 
Estudos mais recentes, entretanto, têm mostrado que, ao interagir em marcos determinados por uma origem étnica nos âmbitos do trabalho, da sociabilidade e do assistencialismo, os emigrados acabam reforçando sua identidade étnica (SOUTELO VÁZQUEZ, 1998, p. 112). Isto é, para alguns membros da Sociedade Espanhola de Socorros Mútuos esta poderia não cumprir uma função econômica, mas certamente possuía um papel simbólico importante.

Operando com algumas teorizações atuais sobre as possibilidades de "manipulação" de identidades dentro de um quadro de opções que também é definido pelo contexto no qual os atores sociais estão inseridos (POUTIGNAT; STREIFF-FENART, 1998, p. 168), podemos sugerir que não se pode definir a priori que as identidades classistas e políticas suplantem as étnicas. Por outro lado, parece claro que a ideologia internacionalista do movimento anarquista das primeiras décadas do século XX tendia a deixar em segundo plano a mobilização com apelo étnico. $\mathrm{O}$ fato de o jornal $A$ dor humana do Sindicato de Ofícios Vários da cidade de Uruguaiana ter sua quarta página redigida em espanhol por Juan Peres - operário sapateiro e militante anarquista no Rio de Janeiro que, quando exilado, circula nas cidades da fronteira brasileira - deve-se ao fato de o periódico servir como jornal operário tanto para Uruguaiana como para a vizinha cidade argentina de Passo de los Libres durante a década de 1920 (CORRÊA, 2010, p. 136 e 158). O internacionalismo operário era uma prática acessível aos libertários da região. ${ }^{13}$

A diferenciação social entre os imigrantes e seus descendentes poderia ser fruto de desdobramentos posteriores para os quais contavam não apenas as qualificações técnicas pregressas, mas também as redes sociais estabelecidas na nova sociedade e os espaços de atuação que esta possibilitava. Alguns dados biográficos disponíveis, particularmente para os emigrados em virtude da Guerra Civil, são bem ilustrativos destas evoluções, como é o caso de Isidro Colet Baulo, um catalão que chegou a Porto Alegre em 1951, com 37 anos, após viver doze anos na França, onde era marceneiro. Por ser "um dos bem-sucedidos industriais de móveis de nossa Capital" no momento da pesquisa de Vargas (1979, p. 189), compôs a galeria de destaques da pesquisadora.

13 Também entre os comunistas o apelo internacionalista podia mobilizar redes de solidariedade que integravam correligionários de várias nacionalidades (NÚÑEZ SEIXAS; FARIAS, 2009, p. 120). 
Estas imigrações mais contemporâneas, de meados do século XX, podem ser estudadas com o recurso da história oral e assim obtemos uma maior riqueza de dados sobre algumas trajetórias. A narrativa de Emílio de La Puerta (PROCHNOW, 2009, p. 59-83), cujo pai foi fuzilado pelo regime franquista, justapõe motivos políticos e econômicos (a família passou fome) ao relembrar a emigração em 1954. Com o ofício de marceneiro, não foi difícil encontrar emprego em São Paulo e, dois anos depois, quando se estabeleceu em Porto Alegre, montou, junto com outro catalão, uma pequena fábrica de móveis e, mais tarde, sua própria oficina. Mesmo que várias trajetórias de ascensão social refiram-se a refugiados políticos, eles não são os únicos trabalhadores qualificados e profissionais que caracterizam a migração transatlântica do pós-Segunda Guerra (KLEIN, 2000, p. 26). O pai de Maria Jesus Centeno fora militar franquista e, após a guerra, trabalhava na Guarda Civil. Para não depender da sogra, uma viúva com um bom padrão de vida, que aceitara o casamento da filha com a condição que o casal residisse com ela, o militar emigrou, chegando com a família em Porto Alegre em 1954. Os primeiros anos foram de muitas dificuldades para a família, mas, após trabalhar como empregado em um café no centro da cidade, o pai da entrevistada tornou-se sócio do proprietário e realizou seu desejo de "juntar dinheiro" (PROCHNOW, 2009, p. 59-89). Estes e outros relatos indicam que a posse de algumas qualificações e o concurso de conterrâneos, num contexto de mercado de trabalho aberto, garantiram a muitos imigrantes uma favorável inserção econômica na nova sociedade, independente das motivações da partida da Europa. ${ }^{14}$

Até a década de 1950, a Sociedade de Socorros Mútuos era a principal protagonista dos espanhóis em Porto Alegre e a articuladora das congêneres do Estado. Havia um segundo protagonista, de atuação mais discreta, em função mesmo de sua existência como órgão de representação estatal, o Consulado, que também possuía reconhecimento na comunidade ${ }^{15}$ e atuava como agenciador dessa em várias situações no Sul do país, como em Pelotas, onde existiu uma Sociedade Espanhola vinculada ao vice-consulado na segunda década do século (LONER, 1999, p. 114). Contudo, quando o

14 Sobre outros casos de alternativas profissionais abertas aos imigrantes na América, estudadas com o recurso dos depoimentos, ver Weber (2010).

15 A Biblioteca da Sociedade de Socorros Mútuos de Porto Alegre, inaugurada na década de 1930, recebeu o nome do cônsul Daniel Fernandez Shaw (VARGAS, 1979, p. 257). 
Consulado, em 1932, envia uma correspondência falando em nome de toda comunidade espanhola, sem que a Sociedade tenha sido consultada, esta protesta, sinalizando seu papel de líder dos espanhóis na cidade (VARGAS, 1979, p. 345). A Guerra Civil na Espanha ativou conflitos entre a Sociedade de Socorros Mútuos e o Consulado, dando origem ao fato histórico mais notável da história dos espanhóis na capital do Estado, a cisão da comunidade emigrada. Esta divisão está sedimentada na memória pela existência de duas entidades, a Socorros Mútuos e a Casa de Espanha, fundada em 1953, a qual agregou velhos membros da Socorros Mútuos não afinados com as posturas fortemente políticas assumidas pelas novas lideranças compostas por refugiados políticos que chegaram ao Rio Grande do Sul no início dos anos 1950. Contudo, a clivagem política ocorreu já na década de 1930 entre a Sociedade e o representante brasileiro do governo rebelde vitorioso (franquista), o Consulado:

Rompe a Sociedade com a representação de seu país, em nossa capital, e só se dispõe a manter relações normais com o Consulado Espanhol quando este representar o governo legalmente constituído na Espanha. O Centro Republicano tomou grande impulso, e seus adversários, por oposição, fundam o Centro Nacionalista. Este centro, também conhecido como "Frente Nacional", teve existência e funcionou ativamente no período de Guerra Civil. Os espanhóis da Sociedade e da colônia estavam divididos (VARGAS, 1979, p. 352).

A defasagem de quase vinte anos na ação do Consulado - de incentivar a fundação de uma entidade alternativa à Socorros Mútuos - certamente está relacionada à mudança de visão do governo espanhol que, nas décadas trinta e quarenta, não tratava os imigrantes de um modo idealizado, tal como aparece na narrativa de Kreling (1979, p. 76):

O Consulado Espanhol compreendia perfeitamente a necessidade de possuir uma Sociedade que mantivesse as tradições espanholas no mais amplo sentido social. Necessitava, também, de um local onde pudesse expandir sua representação, e, nos momentos oportunos, levar a comunicação de suas realizações à colônia espanhola, uma vez que a primitiva Sociedade Espanhola de Porto Alegre não mais comungava de seus ideais, 
havendo se desligado oficialmente dele em 1936. Com uma sociedade organizada e agregada ao Consulado, este manteria e fortaleceria a vinculação com o imigrante, informando-o de seus projetos, leis especiais, manifestações de serviços e atividades que o Estado espanhol se propunha realizar em favor de seus filhos distantes. ${ }^{16}$

As ligações entre o Consulado e a Casa de Espanha permaneceram bastante estreitas. O cônsul e o vice-cônsul foram, respectivamente, presidente e vice-presidente de honra da comissão de redação dos estatutos e encabeçaram a lista dos sócios fundadores da Casa. Durante a construção do prédio da entidade, a partir do final da década de sessenta, o Consulado mediava a contribuição do governo espanhol, enviada pelo Instituto de Emigração Espanhola (KRELING, 1979, p. 115 e 178). O que também pode ter influenciado a ação dos agentes consulares e outros imigrantes, no sentido de incentivar a criação de uma entidade com viés supostamente mais cultural que político, foi a chegada dos refugiados espanhóis exilados na França, que passaram a se agregar na Sociedade de Socorros Mútuos. ${ }^{17}$ Entre os depoimentos destes exilados ou de seus filhos, recolhidos por historiadores, vários são os registros de pertencimento à CNT, a Confederação Nacional do Trabalho, de alinhamento anarcossindicalista. Dos que participaram do governo republicano, o caso mais notório é o do catalão Juan Puig Elias, que ocupou os cargos de Diretor-Presidente da Escola Unificada do Governo da Catalunha e Subsecretário do Ministério da Instrução e Educação do Governo Republicano Espanhol (VARGAS, 1979, p. 185).

O pedagogo emigrou em 1952 e, em Porto Alegre, contando com a doação de livros de vários imigrantes, muitos deles vindos ao Brasil no mesmo navio (PROCHNOW, 2009, p. 94), montou uma livraria, a qual, mesmo não sendo um empreendimento lucrativo, contribuiu para a liderança intelectual de Puig, que, no final da década de 1950, compõe a diretoria da Sociedade de Socorros Mútuos.

16 Sobre a persistência da "lógica policial" em matéria de emigração e sobre a abertura do regime franquista a novas concepções com relação à questão imigratória, no marco da criação do Instituto Espanhol de Emigração, ver Fernández Vicente (2005).

17 Interpretando a interação entre coletividades de imigrantes e coletivos de exilados galegos na América, Núñez Seixas e Farias (2009, p. 121) descrevem casos de politização das disputas internas com tensões entre uma corrente republicana e outra "teoricamente apolítica". 
Na década de 1970, acompanhando as transformações na Espanha, o Consulado volta a ter um novo protagonismo entre os espanhóis, desta vez incentivando o reagrupamento das duas entidades. Em 1977, preocupado com a "desagregação da colônia espanhola em Porto Alegre", o cônsul comparece a reuniões na Sociedade de Socorros Mútuos e na Casa de Espanha (VARGAS, 1979, p. 410), estimulando uma reaproximação entre ambas, o que só se efetivaria na década de noventa, com o surgimento do Clube Espanhol. As dissertações de Iolanda Vargas e Wilma Kreling estão no contexto desta reaproximação e é justificável que tenham sido desenvolvidas na Pontifícia Universidade Católica do Rio Grande do Sul (PUCRS), pois, entre os estabelecimentos de ensino superior do Rio Grande do Sul, foi sempre o que apresentou concentração de intelectuais espanhóis, tanto religiosos como leigos. ${ }^{18}$ Os historiadores do século XXI que buscavam personagens para entrevistas encontraram, no Consulado, Félix Garcez, um dos velhos exilados que fora membro da CNT, ocupando até sua morte no início de 2010 o cargo de Presidente do Conselho de Residentes Espanhóis.

Portanto, a conformação de comunidades étnicas de espanhóis, que são "simultaneamente reais e construídas" (FENTON, 2003, p. 15), que se reconhecem em alguns líderes, que buscam formalizar instâncias de organização, é variável quando observada de um modo diacrônico. Ainda no século XIX, artesãos buscavam amparar uns aos outros por meio do socorro mútuo ("Hoy por ti, mañana por my" é o lema até hoje visível na fachada do prédio que serviu de sede à Sociedade Espanhola de Socorros Mútuos de Porto Alegre); nas primeiras décadas do século XX podemos ter, de um lado, grupos de operários alocados em atividades específicas e com modos de agregamento étnico mais tênues, e, de outro, espanhóis já situados em posições de destaque social, tanto na capital como no interior do Estado, reconhecidos pelos conterrâneos, igualmente empenhados em obter êxito social e econômico, como aqueles que representam o grupo perante a sociedade mais ampla. Se, com o avançar das décadas, havia diferenças políticas que os dividiam, os imigrantes espanhóis do Sul do país, por outro lado, se beneficiaram de uma experiência já acumulada por outros imigrantes,

18 Ao promover um curso da "língua pátria" em seu primeiro ano de existência (1954), a Casa de Espanha contou com a subvenção do Consulado e a disponibilização de salas da Pontifícia Universidade Católica (KRELING, 1979, p. 214). Para localizar depoentes para suas pesquisas, Prochnow (2009, p. 17) contou com mediações de funcionários desta instituição. 
particularmente dos países platinos vizinhos, e assim dispunham, desde o século XIX, de modelos e influências para constituir entidades associativas (socorros mútuos) e objetivar memórias (Panteon dos pioneiros), as quais contribuíam para endossar representações identitárias.

Tiveram contato também com uma representação mais elaborada, a de "hispanidade", que é associada à conquista da América e aos hispano-americanos, pelo menos na forma como é divulgada pelos intelectuais das populações emigradas (FERRER, 1964). ${ }^{19}$ Que os imigrantes sejam vistos como continuadores modernos da obra dos conquistadores é uma imagem que pode ter seu correlato no fato de que os espanhóis buscavam a "América", independente do país em que tenham se estabelecido. Entre os depoimentos daqueles - imigrantes ou descendentes - que estão no Brasil, são muito frequentes os relatos de viagens cujo destino original era outro país da América do Sul, especialmente Venezuela, Argentina ou Uruguai, ou de parentes que se instalaram em algum destes países (WEBER, 2010; PROCHNOW, 2009). Esta construção simbólica, que remete ao que a teoria sobre etnicidade denomina identidade "globalizante" (POUTIGNAT; STREIFF-FENART, 1998, p. 144), tem, por um lado, a vantagem de facilitar a articulação das comunidades emigradas na América, mas, por outro, dificulta a distintividade dos espanhóis, particularmente no Brasil, com relação aos emigrados de países hispano-americanos. ${ }^{20}$ Entidades e publicações binacionais, a par de ideologias de solidariedade internacional operária, dificultam o cultivo de identidades étnicas referenciadas a estados-nações nestes limites do país onde as fronteiras do estado territorial têm porosidade.

Representações possuem sempre bastante plasticidade e não se pode a priori saber qual contexto que irá favorecer esta ou aquela imagem. $\mathrm{O}$ anarquismo do início do século XX pode ter afastado alguns imigrantes espanhóis de entidades de cunho étnico e supraclassista, mas a "comunidade política", que Max Weber (1994, p. 270) situa como fator que fomenta a comunhão étnica, embasa os liames entre os espanhóis desterritorializados de meados do século, que passam a utilizar a entidade como espaço sim-

19 A conferência de Ferrer, presidente do Instituto Argentino de Cultura Hispânica de Córdoba, foi pronunciada durante um curso para candidatos às bolsas oferecidas pelo Instituto de Cultura Hispânica de Madri.

20 O jornal El Oriental aparece como obra dos imigrantes espanhóis na cidade de Bagé em 1912 (KRELING, 1979, p. 32), cidade próxima à fronteira do Brasil com a "República Oriental del Uruguay". 
bólico e político, que conecta o passado do além-mar e o presente em uma outra sociedade. Quando as ações e as representações dos grupos sociais se manifestam deixando registros, os historiadores que se ocupam em explicá-las dispõem de mais elementos para estudá-las.

A prática historiográfica, entretanto, não se realiza de modo isolado, operando sempre dentro de um "campo" de estudos que possui referenciais que vão se constituindo por meio dos debates acadêmicos. Nesse sentido, o estudo de qualquer grupo étnico no Rio Grande do Sul, particularmente daqueles que se formaram em decorrência do processo imigratório de europeus para a América, dificilmente deixa de ter como contraponto a vasta produção bibliográfica sobre a imigração alemã e italiana, a qual, por sua vez, não pode ser desvinculada da institucionalização de práticas étnicas que, em virtude da ação de camadas médias intelectualizadas, atingem expressão em editoras, congressos específicos e entidades universitárias e, em alguns casos, passaram a caracterizar o perfil de algumas cidades oriundas do processo de colonização. ${ }^{21}$ Avaliar o caso espanhol por esta perspectiva comparativa não decorre de um esforço de escalonamento de grupos étnicos em função de sua visibilidade através da produção histórica, mas sugere aguçar o olhar para um grupo que tem estado, até o momento, pouco presente em pesquisas de cunho acadêmico. O que este artigo propõe é que há uma relação entre a produção histórica sobre determinado grupo e a sistematização de práticas deste mesmo grupo (calendário de festas, associações com reuniões periódicas, publicações com alguma regularidade, divulgação destas atividades etc.), pois são estas ações com algum nível de institucionalização que geram registros históricos. Tais práticas, por sua vez, não podem ser dissociadas do sucesso dos membros do grupo em promover identidades agregadoras. Como visto acima, havia forças centrífugas que não favoreciam uma identidade "espanhola": internacionalismo de classe, cisão na comunidade por razões políticas, identidades de nível mais amplo ("hispanidade") e mais restrito que a identidade de origem com referência à nação (o regionalismo $)^{22} \mathrm{e}$ a própria dificuldade de muitos emigrados em identificar-se com uma nação de origem que, por décadas, esteve associada

21 Estas considerações estão desenvolvidas em Weber (2011).

22 O regionalismo espanhol, que se manifesta também nas comunidades emigradas, foi pouco analisado neste artigo. Para citar um exemplo, relativo ao caso cubano, veja Carmen Barcia (1999). 
ao franquismo. Portanto, a análise do grupo espanhol, a partir do estudo da comunidade que se estabeleceu no Rio Grande do Sul, se não deixa de lado teorizações de alcance mais amplo, demanda compreensão de várias especificidades.

\section{Referências}

BELLOMO, Harry Rodrigues. A produção da estatutária funerária no Rio Grande do Sul. In: . (Org.). Cemitérios do Rio Grande do Sul: arte, sociedade, ideologia. 2. ed. Porto Alegre: EDIPUC-RS, 2008. p. 23-38.

BILHÃO, Isabel Aparecida. Identidade e trabalho: análise da construção identitária dos operários porto-alegrenses (1896-1920). Tese (Doutorado) - Universidade Federal do Rio Grande do Sul. Programa de Pós-Graduação em História, Porto Alegre, 2005.

CANEZ, Anna Paula M. Fernando Corona e os caminhos da arquitetura moderna em Porto Alegre. Porto Alegre: Unidade Editorial Porto Alegre, 1998.

CARMEN BARCIA, M. Del. A sociabilidade formal: os centros rexionais españois en Cuba. Estudios Migratorios, n. 7-8, p. 77-94, 1999.

CHARÃO, Egiselda B. O sagrado e o profano nos cemitérios de Bagé/RS. Revista Digital Estudios Historicos. Centro de Documentación del Rio de La Plata. Montevideu. ag. 2009. n. 2. Disponível em: <http://www.estudioshistoricos.org/edicion_2/ egiselda_charao.pdf $>$. Acesso em: 13.08.2010.

CORRÊA, Anderson R. Pereira. Movimento operário em Alegrete: a presença de imigrantes e estrangeiros (1897-1929). Dissertação (Mestrado) - PUC-RS, Programa de Pós-Graduação em História. Porto Alegre, 2010.

FENTON, Steve. Etnicidade. Lisboa: Instituto Piaget, 2003.

FERNÁNDEZ VICENTE, María José. En busca de la legitimidad perdida. La política de emigración del régimen franquista, 1946-1965. Estudios Migratorios Latinoamericanos, v. 19, n. 56, p. 3-29, 2005.

FERRER, Manuel Augusto. En torno a la idea de la hispanidad. Córdoba: Instituto Argentino de Cultura Hispánica, 1964. 16 p.

GANS, Herbert J. Symbolic Ethnicity: The future of ethnic groups and cultures in America. In: SOLLORS, Werner (Ed.). Theories of ethnicity: a classical reader. New York: New York University Press, 1996. p. 424-459. 
HOMENAGEM AO PROFESSOR IGNACIO MONTANHA. Porto Alegre. Of. Gráficas da Livraria do Globo, 1928.

INSTITUTO BRASILEIRO DE GEOGRAFIA E ESTATÍSTICA. Biblioteca do IBGE na internet (portal). Disponível em: < http://biblioteca.ibge.gov.br/>. Acesso em: 12/03/2009.

KLEIN, Herbert S. Migração internacional na História das Américas. In: FAUSTO, B. (Org.). Fazer a América: a imigração em massa para a América Latina. 2. ed. São Paulo: EDUSP, 2000. p. 13-31.

KLOVAN, Felipe Figueiró. Sob o fardo do ouro negro: as experiências de exploração e resistência dos mineiros de carvão do Rio Grande do Sul na primeira metade da década de 1930. Trabalho de Conclusão de Curso. Departamento de História UFRGS. Porto Alegre, 2009.

KRELING, Wilma F. História da Casa de Espanha de Porto Alegre. Dissertação (Mestrado em História) - PUC-RS. Porto Alegre, 1979.

LONER, Beatriz Ana. Classe operária: mobilização e organização em Pelotas: 1888-1937. Tese (Dourado em Sociologia) - UFRGS. Porto Alegre, 1999.

NÚÑEZ SEIXAS, Xosé M. Modelos de liderazgo en comunidades emigradas. Algunas reflexiones a partir de los españoles en América. In: BERNASCONI, A.; FRID, C. De la Europa a las Américas: dirigentes y liderazgos (1880-1960). Buenos Aires: Biblos, 2006. p. 17-41.

; FARIAS, Ruy. Transterrados y emigrados: una interpretación sociopolítica del exílio gallego de 1936. Arbor. Ciencia, Pensamiento y Cultura, Madrid, n. 735, p. 113-127, en.-feb. 2009.

PERES, Elena P. A inexistência da terra firme: a imigração galega em São Paulo, 1946-1964. São Paulo: Editora da Universidade de São Paulo/FAPESP/Imprensa Oficial do Estado. 2003.

POUTIGNAT, P.; STREIFF-FENART, J. Teorias da etnicidade. São Paulo: Editora da UNESP, 1998.

PROCHNOW, Lucas N. Memórias, narrativas e história: a imigração espanhola recente em Porto Alegre. Dissertação (Mestrado em História) - PUC-RS. Porto Alegre, 2009.

SCHMIDT, Benito Bisso. O patriarca e o tribuno: caminhos, encruzilhadas, viagens e pontes de dois líderes socialistas - Francisco Xavier da Costa (187?-1934) e Carlos Cavaco (1878-1961). Tese (Doutorado em História) - Universidade Estadual de Campinas. Campinas, 2002.

SEYFERTH, Giralda. Imigração e cultura no Brasil. Brasília: Editora da UnB, 1990. 
SILVA JR., Adhemar Lourenço da. As sociedades de socorros mútuos: estratégias privadas e públicas (estudo centrado no Rio Grande do Sul-Brasil, 1854-1940). Tese (Doutorado em História) - Pontifícia Universidade Católica do Rio Grande do Sul. Porto Alegre, 2004.

SILVA, Érica Sarmiento da. Galegos no Rio de Janeiro (1850-1970). Tese (Doutoral) - Universidade de Santiago de Compostela. Facultad de Geografía e História. Santiago de Compostela, 2006.

SOCIEDAD ESPAÑOLA DE SOCORROS MUTUOS DE PORTO ALEGRE. Registro General de Socios desde la Fundación, 1893. Libro Protocolo. Registro general de los socios fundadores y de todos los proymentes para socios en la Sociedade Española de Socorros Mutuos de Porto Alegre, fundada en $1 .^{\circ}$ de agosto de 1893. Porto Alegre.

SOUTELO VÁZQUEZ, R. Memoria oral y identidad étnica da inmigración española a Latinoamérica en el siglo XX: los gallegos en Brasil, 1880-1970. Estudios Migratorios, n. 6, p. 97-124, 1998.

VARGAS, Iolanda Guimarães. História da Sociedade Espanha de Socorros Mútuos de Porto Alegre. Dissertação (Mestrado em História) - Pontifícia Universidade Católica do Rio Grande do Sul. 518 p. Porto Alegre, 1979.

WEBER, Max. Economia e sociedade. 3 ed. v. 1. Brasília: Editora da UnB, 1994.

WEBER, Regina. Grupos étnicos, estratégias étnicas. In: SIDEKUM, A.; ARENDT, I.; GRÜTZMANN, I. Campos múltiplos: identidade, cultura e história. São Leopoldo: Nova Harmonia/Oikos, 2008. p. 235-255.

. Galegos no sul do Brasil: alternativas na América. Anos 90, v. 17, n. 31, p. 83-109. jul. 2010. Disponível em: <http://seer.ufrgs.br/index.php/anos90/index>.

. Estudos étnicos no Rio Grande do Sul: análise historiográfica. In: HERÉDIA, Vania Beatriz M.; RADÜNZ, Roberto (Org.). História e imigração. Caxias do Sul: EDUCS, 2011. p. 269-283.

WOORTMANN, Ellen F. Identidades e memória entre teuto-brasileiros: os dois lados do atlântico. Horizontes Antropológicos, Porto Alegre, ano 6, n. 14, p. $205-$ 238, nov. 2000.

ZUBILLAGA, Carlos. Notas para una tipología de los liderazgos en la inmigración española en Uruguay, 1870-1960. Estudios Migratorios Latinoamericanos, v. 15, n. 44 , p. 147-163, 2000.

Recebido em fevereiro de 2012.

Aprovado em abril de 2012. 